This document is published in:

Materials Letters, Volume 65, Issue 14, 31 July 2011, Pages 2152-2154

DOI: http://dx.doi.org/10.1016/j.matlet.2011.04.083

(c) 2011 Elsevier B.V. 


\title{
Experimental study of agglomerated-cork-cored structures subjected to ballistic impacts
}

\author{
S. Sanchez-Saez ${ }^{\mathrm{a}, *}$, E. Barbero ${ }^{\mathrm{a}}$, J. Cirne ${ }^{\mathrm{b}}$ \\ a Department of Continuum Mechanics and Structural Analysis, University Carlos III of Madrid, Avda. de la Universidad 30, 28911 Leganés, Madrid, Spain \\ b Structural Integrity Group, Mechanical Engineering Department, University of Coimbra, 3030-788, Coimbra, Portugal
}

\section{A R T I C L E I N F O}

Article history:

Received 30 September 2010

Accepted 24 April 2011

Available online $\mathrm{xxxx}$

Keyword:

Aerospace materials

Metals and alloys

Agglomerated cork

High-velocity impact

Ballistic limit

\begin{abstract}
A B S T R A C T
The present paper examines the high-velocity impact behaviour of agglomerated cork-cored structures. The ballistic performance was studied by impact-perforation tests. Three different types of specimens were tested: an agglomerated cork, two spaced thin aluminium plates, and a pair of thin aluminium plates separated by an agglomerated-cork core. The behaviour of the agglomerated cork and the effects of the cork core were analysed in terms of the ballistic limit, residual velocity, and energy absorption. The ballistic limit of cork-cored structures increased slightly, whereas the absorbed energy was strongly augmented by the presence of the cork core.
\end{abstract}

(C) 2011 Published by Elsevier B.V.

\section{Introduction}

Aerospace components need to have high strength-to-weight ratios in order to build lightweight structures. Sandwich structures with strong stiffness and high strength-to-weight ratios are widely used as structural components in many industrial applications. The commonly used core materials are honeycombs, foams, and balsa wood, but recent developments have resulted into new alternatives, such as natural materials with cellular morphologies [1]. A sandwich panel with a cellular core has excellent energy-dissipating performance and a weight-saving advantage, and thus can be used as an energy absorber in a wide range of applications under extreme loading conditions such as ballistic impact [2].

The properties of a material required to be used as a core in sandwich structures have low density, high shear modulus, high shear strength, strong stiffness perpendicular to the faces, and good thermal as well as acoustic insulation [1]. Agglomerated cork can be considered as an alternative for the sandwich core, since cork is a natural cellular material with some remarkable properties, such as high damage tolerance to impact loads, good thermal and acoustic insulation and excellent damping characteristics for the suppression of vibrations. Also, cork, as a natural material, is renewable and easily recycled.

Although agglomerated cork has been applied in thermal-protection systems for spacecraft or structural elements for lightweight airplanes $[3,4]$, it is definitely a complex cellular material with quite unknown or not well-understood mechanical properties [5]. Research on the mechanical behaviour of agglomerated cork is limited to a small number

\footnotetext{
* Corresponding author. Tel.: +34916248882; fax: +34916249430

E-mail address: ssanchez@ing.uc3m.es (S. Sanchez-Saez).

URL: http://www.uc3m.es/mma/ (S. Sanchez-Saez).
}

of published studies [6]. Data are available on static experimental characterization from compression tests [5,6], tensile tests [6], shear tests [7], three-point bending tests [1,7-9], and creep tests under compression [10]. Fewer studies have been conducted under dynamic conditions: dynamic compressive tests $[5,11]$ and vibration-based tests [6].

However, the mechanical behaviour of cork when subjected to impact has not yet been thoroughly investigated, since the studies in the literature generally focus on strain rates of less than $10^{-1} \mathrm{~s}^{-1}$ [5]. Castro et al. [1] carried out low-velocity impact tests in a drop tower, and Petit et al. [12] performed low-velocity impact tests and CAI tests. However, information is still lacking on the ballistic impact behaviour of these structures with agglomerated-cork cores.

Therefore, the purpose of this study is to analyse the ballistic behaviour of agglomerate-cork-cored structures. In this study, the sandwich-panel structures investigated can be thought of as a pair of thin aluminium plates separated by a core of agglomerate cork. Impact perforation tests were performed to study their ballistic behaviour. The effects of the cork core presence on the ballistic limit, projectile residual velocity, and energy absorption during penetration were analysed.

\section{Experimental procedure}

\subsection{Specimens}

To study the high-velocity impact behaviour of the agglomerated cork, and the effect of the cork presence as core in the sandwich structures, three different types of specimens were tested (Fig. 1): an agglomerated cork $37 \mathrm{~mm}$ thick, two thin aluminium plates $(1.7 \mathrm{~mm})$ spaced $37 \mathrm{~mm}$, and a pair of thin aluminium plates separated by agglomerate cork. 


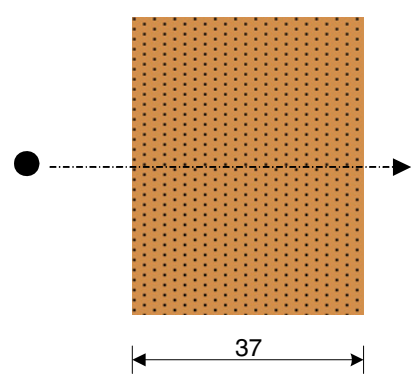

a) Agglomerated cork

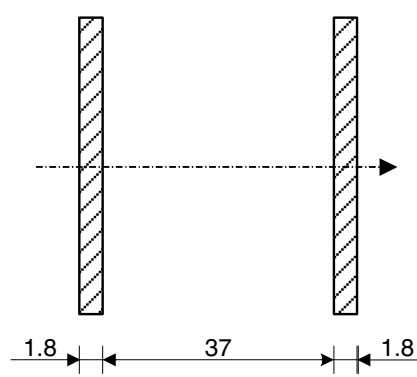

b) Aluminium

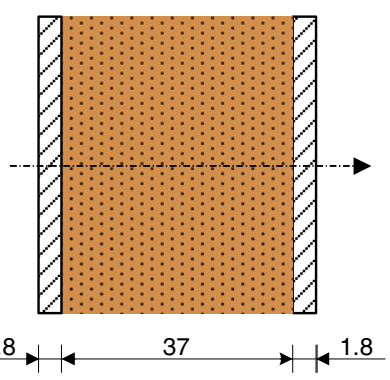

c) Agglomerated cork + Aluminium

Fig. 1. Configurations tested.

The material of the plates was 6063-T5 aluminium alloy and the core was a commercial agglomerated cork, made from a mixture of cork particles and a polymeric binder.

\subsection{Experimental devices}

A gas gun, Sabre Ballistics model A1G +, was used in the ballistic tests. A total of 55 specimens were tested at various impact velocities from 130 to $680 \mathrm{~m} / \mathrm{s}$, using spherical steel projectiles of $7.5 \mathrm{~mm}$ in diameter and mass of $1.7 \mathrm{~g}$. The impact velocity was varied by changing the pressure in the gas gun. Specimens were rigidly fixed to a support device.

All the tests were recorded by a high-speed video camera PHOTRON FASTCAM-ultima APX. The data-acquisition system of the camera was adjusted to gather information in a window of 50,000 frames per second. For better recording quality, a high-intensity light source, model ARRISUN 12 plus, was used. From the information provided by the camera, the impact and residual velocities were calculated, evaluating the distance travelled by the projectile in several consecutive frames.

\section{Results}

The residual velocity of the projectile after perforation is shown in Fig. 2, for all the specimens tested. Due to the difficulty of controlling impact velocities precisely and the existence of a zone of mixed results in which a projectile may completely perforate or only partially

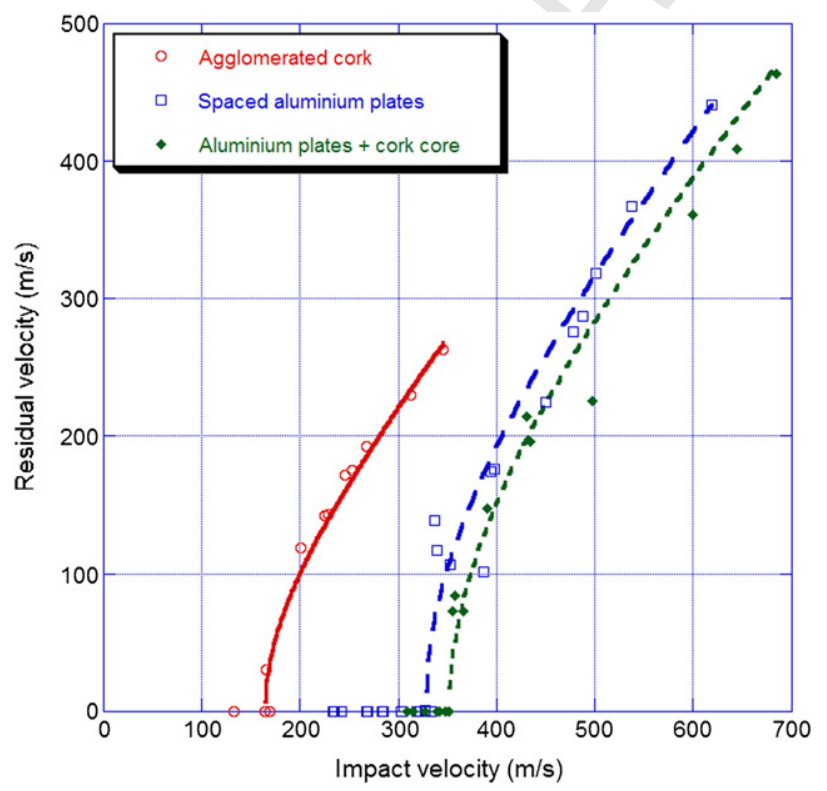

penetrate under apparently identical conditions, the ballistic limit could not be calculated in a deterministic way [13]. The ballistic limit was defined as the minimum impact velocity required for the projectile to completely penetrate the specimen. In this work the ballistic limit was estimated by fitting an equation to the experimental data by the least-squares method.

The fitting curves shown in Fig. 2 were calculated using the LambertJonas model [14] which relates residual velocity to impact velocity by means of the following equation:

$v_{R}=A \cdot\left(v_{o}^{p}-v_{B L}^{p}\right)^{1 / p}$

where $\mathrm{v}_{\mathrm{o}}$ is the impact velocity of the projectile, $\mathrm{v}_{\mathrm{BL}}$ the ballistic limit, $V_{R}$ the residual velocity of the projectile, and $A$ and $p$ are empirical parameters. In this study, the value of $\mathrm{p}$ was 2 , as is usual in the literature. $\mathrm{v}_{\mathrm{BL}}$ and $\mathrm{A}$ were estimated by a least square fitting method, varying the parameter A from 0.8 to 0.9 .

Table 1 shows the ballistic limit estimated by this equation for all the components tested. The ballistic limit of agglomerated cork was

Table 1

Ballistic limit for the specimens tested.

\begin{tabular}{ll}
\hline Specimens & Ballistic Limits $(\mathrm{m} / \mathrm{s})$ \\
\hline Cork & 160 \\
Aluminium & 323 \\
Aluminium + cork & 348 \\
\hline
\end{tabular}

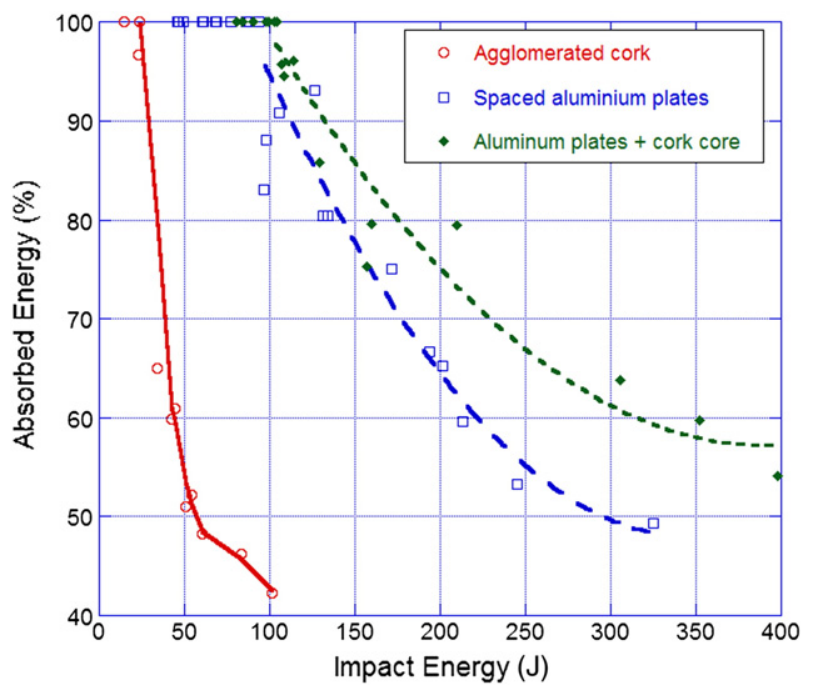

Fig. 3. Absorbed energy vs. impact energy. 


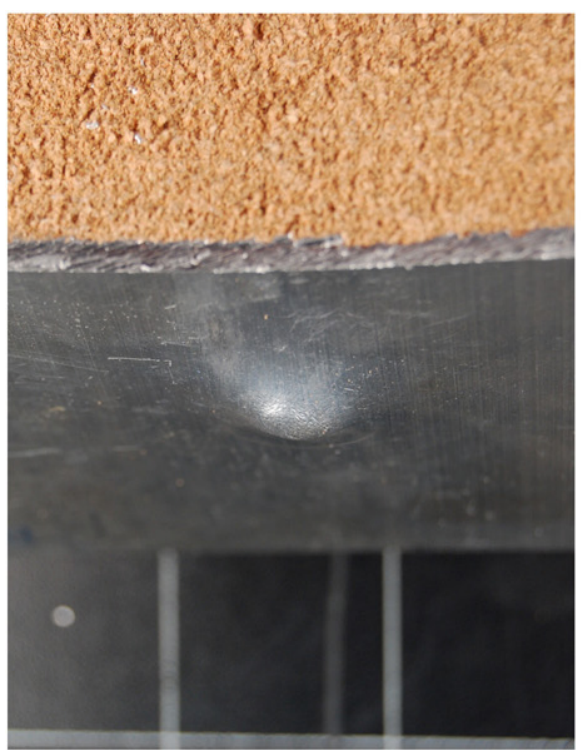

a

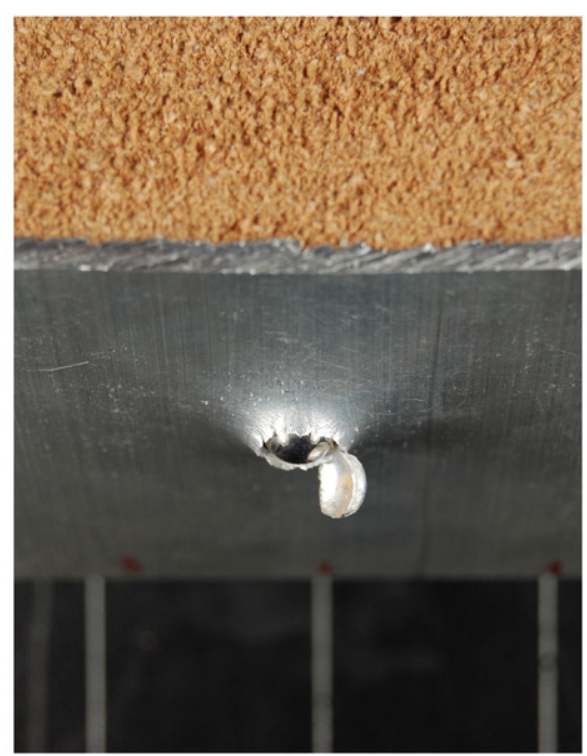

b

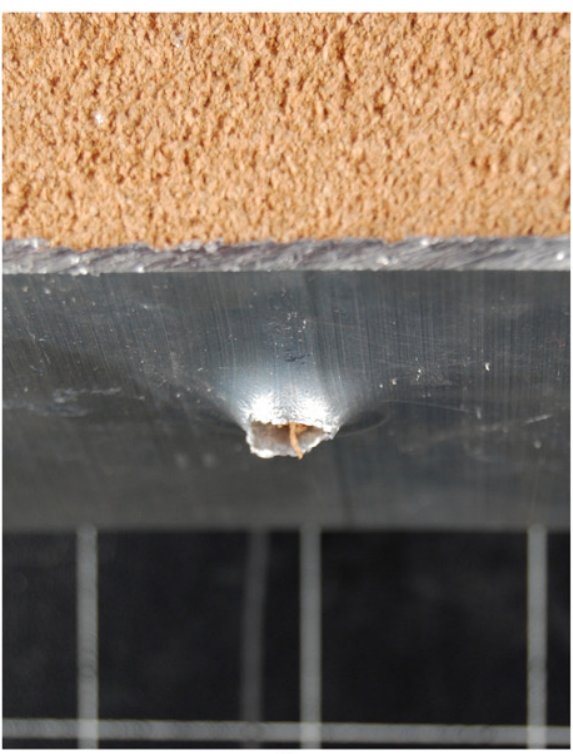

C

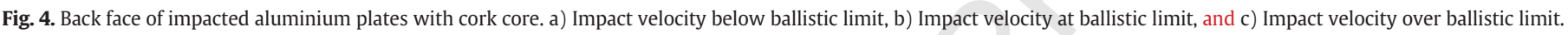

approximately half that of the aluminium plates. When an agglomeratedcork core is placed between the two aluminium plates, the ballistic limit increases by a $7.7 \%$.

The energy absorbed in the perforation process was estimated for several impact energies for agglomerated cork, aluminium plates, and aluminium plates with cork core (Fig. 3 ). The absorbed energy by the agglomerate cork diminished rapidly to very low values at impact velocities that resulted in the complete perforation of the spaced aluminium plates. By contrast, the decrease of the absorbed energy by the spaced aluminium plates was less pronounced. There were significant differences in the absorbed energy by the aluminium plates when the cork core was added. Thus, for example, at an impact energy of $300 \mathrm{~J}$ the presence of the cork core accounted for approximately a $30 \%$ increase in the absorbed energy by the structure.

The morphology of the damage did not change when a core of aglomerated cork was added. In all the cases the damage appeared in a narrow area around the impact point in the back face of the structure. The damage evolution started from plastic deformation below ballistic limit (Fig. 4a), to shear plugging (Fig. 4b) and petalling (Fig. 4c), when the impact velocity increased over the ballistic limit. The formation of a shear plug can be seen especially at impact velocities slightly higher than the ballistic limit.

\section{Conclusions}

In this work the ballistic behaviour of agglomerated cork and its influence in the behaviour of aluminium thin plates subjected to highvelocity impacts of a low-mass projectile were studied.

The ballistic limit of the agglomerated cork is low, being approximately half of the ballistic limit of the thin aluminium plates. The absorbed energy by agglomerated cork diminishes rapidly once the complete perforation of the plate has occurred. By contrast, the absorbed energy for the aluminium plates decreases more slowly when the impact energy increases.

The additions of a core cork to a structure made from two thin aluminium plates did not alter the failure mechanisms of the plates. An increase in the ballistic limit and especially of absorbed energy at impact velocities that cause perforation is observed when cork core is included.

\section{Acknowledgements}

The authors are indebted to the Spanish Ministerio de Educación y Ciencia (Project HP2006-0024) and the Portuguese Ministério da Ciência, Tecnologia e Ensino Superior for the financial support of this work; also to Amorim Cork Composites for providing the agglomerate cork used in the tests.

\section{References}

[1] Castro O, Silva JM, Devezas T, Silva A, Gil L. Cork agglomerates as an ideal core material in lightweight structures. Mat\&Des 2010;31:425-32.

[2] Hou W, Zhu F, Lu G, Fang D-N. Ballistic impact experiments of metallic sandwich panels with aluminium foam core. Int J Impact Eng 2010;37:1045-55.

[3] Díaz-Parralejo A, Díaz-Díez MA, Macías-García A, Rosa-Blanco de la P, Gómez Serrano V. Bending strength of black and composite agglomerates of cork. Mater Lett 2003;57(24-25):4004-8.

[4] Pereira H. Cork: Biology, Production and Uses. Elsevier; 2007.

[5] Gameiro CP, Cirne J, Gary G. Experimental study of the quasi-static and dynamic behaviour of cork under compressive loading. J Mater Sci 2007;42:4316-24.

[6] Moreira RAS, de Melo FJQ, Rodrigues JFD. Static and dynamic characterization of composition cork for sandwich beam cores. J Mater Sci 2010;45:3350-66.

[7] Reis L, Silva A. Mechanical behaviour of sandwich structures using natural cork agglomerates as core materials. J Sand Struct Mat 2009;11:487-500.

[8] Kim S, Wallace D. Designing and testing of cork composite core material. In: Ravichandran G, editor. 9th International conference on Sandwich Structures; 2010.

[9] Silva JM, Devezas T, Silva A, Gil L, Nunes C, Franco N. Exploring the use of cork based composites for aerospace applications. Mat Sci Forum 2010;636-637: 260-5.

[10] Mano JF. Creep-recovery behaviour of cork. Mat Lett 2007;61:2473-7.

[11] Gameiro CP, Cirne J. Dynamic axial crushing of short to long circular aluminium tubes with agglomerate cork filler. Int J Mech Sci 2007;49(9):1029-37.

[12] Petit S, Bouvet C, Bergerot A, Barrau J-J. Impact and compression after impact experimental study of composite laminate with a cork thermal shield. Compos Sci Technol 2007;67:3286-99.

[13] MIL-STD-662F Standard. $V_{50}$ Ballistic test for armor. Department of Defense Test Method Standard 1997.

[14] Kasano $\mathrm{H}$. Recent advances in high-velocity impact perforation of fiber composite laminates. JSME Int Journal 1999;42(2):147-57. 